\title{
The Role of States in Controlling the Obesity Epidemic, and a Personal Autonomy to Decide
}

\author{
Priscila Rosa da Fonseca ${ }^{1}$, Ana Maria Anjo Toloi ${ }^{1}$, Larissa Bianca Paiva Cunha de Sá1, \\ Alberto Krayyen Arbex ${ }^{1,2,3}$ \\ ${ }^{1}$ Division of Endocrinology, IPEMED Medical School, São Paulo, Brazil \\ ${ }^{2}$ Diabetology Department, MalteserKrankenhaus St. Franziskus-Hospital, Flensburg, Germany \\ ${ }^{3}$ PPGBIOS, Fundação Oswaldo Cruz, Rio de Janeiro, Brazil \\ Email: pri.rosadafonseca@gmail.com, albertoarbex@gmail.com
}

How to cite this paper: da Fonseca, P.R., Toloi, A.M.A., de Sá, L.B.P.C. and Arbex, A.K. (2017) The Role of States in Controlling the Obesity Epidemic, and a Personal Autonomy to Decide. Open Journal of Endocrine and Metabolic Diseases, 7, 3543.

http://dx.doi.org/10.4236/ojemd.2017.71004

Received: November 8, 2016

Accepted: January 3, 2017

Published: January 6, 2017

Copyright (๑) 2017 by authors and Scientific Research Publishing Inc. This work is licensed under the Creative Commons Attribution International License (CC BY 4.0).

http://creativecommons.org/licenses/by/4.0/

\begin{abstract}
Obesity has reached pandemic proportions in the world. Who is to blame for this: the person or the State (or both?). An increase in diseases associated with excess weight is also worldwide reported, such as Diabetes, Hypertension and some types of cancers. Therefore, the economic impacts of these comorbidities are an important issue to be discussed by States and citizens. Although the World Health Organization (WHO) has set and classified obesity as a disease more than 30 years ago, the American Medical Society was until recently (2010) not so sure about this definition. This article discusses the relevance of the implementation of public health policies for prevention and control of obesity, along with the possible ethical limitations to these actions, considering the autonomy of individuals regarding their health.
\end{abstract}

\section{Keywords}

Obesity, Comorbidities, Public Health Policies, Autonomy of the Citizen

\section{Introduction}

Treating obesity no longer simply means to treat only the person affected by obesity. Currently, the global epidemic that corresponds to excess weight affects more than half the world's population, and its prevalence is rising, especially in developing countries, such as Latin American countries, Africa and some parts of Asia. Who is to blame for this: people or governments? Or should both be held responsible for looking after solutions? A thorough and broader analysis of regulatory issues involving the control of overweight is mandatory, along with a 
better understanding of its determinants in such countries, which face one of their greatest challenges in public health when dealing with such harm to the health of their citizens.

\section{Legal Aspects of Obesity and Health}

Many national Constitutions show specific approaches towards the right to health nowadays. The Brazilian Federal Constitution of 1988, also known as "Citizen's Constitution" describes in the Articles 196-202 the right of every Brazilian citizen to health, considering that health is "a right of all [citizens] and a duty of State" (F.C. 1988, article 196) [1]. Thus, it seems that this State becomes responsible in a comprehensive way to health, "lato sensu", that is, not only for treating diseases such as obesity, but also regarding their prevention-which is particularly true for chronic diseases. Such a prevention happens in a multidisciplinary way and involves wide aspects of Public Health Policies in developing countries, such as regulation of food legislations within the countries, control and periodic measurement of health problems associated with excess weight and also the need to build prospects on the natural history of the disease, its evolvement among populations and to anticipate trends of its increase in prevalence [2] [3].

\section{Government Power}

In Brazil, the prevention of diseases historically have a repressive profile, such as past examples of successful eradication campaign of Yellow Fever in the first decades of the 20th century, commanded by the Researcher Oswaldo Cruz in Rio de Janeiro [4] [5], and also by the episode known as the "Vaccine Revolt", in which citizens were unwilling to subjugate their personal health decisions to officers and authorities that worked very much apart of their realities, in distant government rooms [6] [7].

Nowadays excess weight affects more than $50 \%$ of the Brazilian population, and around $20 \%$ of the whole population has obesity [8]. These numbers are very close to other prevalence numbers in Latin America. A person affected by obesity has, according to many observational prevalence studies, a higher frequency of comorbidities such as diseases like hypertension and especially diabetes, which clearly involve higher health costs for the State [9]. A recent research regarding the costs of obesity in Brazil found an important increase in values spent by the Brazilian government, divided among the primary, secondary and tertiary health care levels [10]. Therefore it is important to understand that the reasons for the intervention of the State on health care do not simply imply the individual health-i.e., a person's health status-but there is also a strong economic interest of the State in the high amounts of money and investment involved in maintaining the health of its population as a whole, through the Unified Health System of Brazil, a.k.a. 'SUS', and involve a significant percentage of the national Gross Domestic Product of the country [11].

In addition to these aspects of national financial control, increasing state 
intervention in the health of their fellow citizens is not unique to Brazil. The regulation of health in the world involves "biopower" mechanisms widely described in the literature, and has in Michel Foucault its most important exponent [12] [13]. Foucault describes in his works the processes through which citizen delegate to the state the task of organizing and "categorizing" people through biological characters as "healthy" or "not healthy", and his work is essential to understand the historical process of public health control systems, along with Canguilhem, who described, more than 70 years ago, how the building of parameters of what is normal and which, instead, will become pathological, is the landmark of modern medicine and public health [14].

Other authors such as Esposito, Mahieu, Revel and Agamben have taken Foucault's legacy far beyond his origins, assisting and deepening this understanding of the state control on the private health of citizens worldwide [15] [16] [17] [18] [19].

\section{A Citizen's Autonomy}

Up to which extent does a person/a citizen has the autonomy to decide about his/her health status?

This is a current and relevant issue and possibly the core of this analysis. Biopower has taken the empty positions of this process of "categorization" of citizens on behalf of their health, and the state acts in its own interest (not the citizen's), perhaps as a "Leviathan", frequently without taking into account the own individual view of each citizen [20]. In a certain sense, we return to the saga of John Landless in Britain, as the Magna Carta of England was issued, in the year of 1215, and for the first time in history a "right to due process" was registered, beginning a "Streit" between the citizen and the State for the control of societies [21].

Obesity as a disease is itself a definition that until recently was under strong questioning by representative bodies of the official health community, especially in the United States [22] [23]. Although WHO in the late twentieth century had already defined obesity as a disease (or health outcome) [24] and attributed it to an specific International Classification of Diseases (ICD) [25], the American Medical Society by 2012 had not yet developed a favorable consensus to define obesity as a disease [26] — which would lead to the need for the construction of public and private health policies towards its control and treatment-i.e., more costs to finance "the war on obesity". This key point is especially worth of attention, because the cost of obesity depends essentially that health plans (for the United States of America) and health authorities (for the rest of the world countries) recognize obesity as a disease, directly associated with other health problems, and this proven association as a strong evidence, through definitive scientific studies, would support health decisions and an increase in health financing [27] [28].

According to a report on Obesity issued by the American Medical Society in 2010, there were not so far enough scientific reasons to define obesity as a disease. 
The reasoning for this was that although obesity was associated with other diseases among populations, in the individual this association was not entirely relevant or consistent [29]. As a matter of fact, the last 10 years have witnessed a controversy from studies describing the "Obesity Paradox", which is an aspect of "protection" offered by some degree of excess weight, that was clear when patients had higher levels of obesity [30] [31]. This stood against the logic thought that there would be a linear association of the degree of obesity with the prevalence of comorbidities, most necessarily by the prevalence of diseases associated with overweight [32].

A work of 2013 entitled "What's wrong with fat?" [33] made it clear that, individually, many American citizens were questioning their therapists about whether there would be a real risk of being overweight, when lifestyle to these same persons would be an individual choice to be exercised with autonomy, and not as a burden [34].

In fact, in a society oriented by liberal values such as the United States of America, where the intervention of the State over the individual is execrated and strongly repudiated [35], it is understandable that individuals will argue and oppose a possible health system in which decisions would be taken solely by "health authorities" and not by the individual [36].

A different reality occurs in Latin American societies, in which state intervention is usually more concrete [37] [38], and acts in conjunction with the initiatives of individuals, in order to possibly achieve balanced results between collective interest and individual plans [39] [40].

Such facts result from differences in historically diverse social values, not only influencing the organization of health systems in each country and culture, but also determining the consequences of such health systems for their individuals.

\section{Unavailability of the Human Body}

Since the Roman law there is a debate on the rights of personality, especially on the human body. At that time the body already belonged to the State. The figure of the "habeas corpus" was created in order to guarantee the right of freedom of the Roman citizen [41].

The influence of Roman law on our legal structure is undeniable and highly noticeable. Nowadays the ethical justification is questioned in specific situations such as in organ donations. However, as a general role, the state defines the limits of the use of out body [42].

This debate is directly related to the topic of our thesis. The autonomy of the individual to decide their health behaviors, and body weight levels compatible with the welfare and the choices of each person are faced with ideals defined by statistical averages, that exclude from this definition the individual freedom and the choice to decide about what to do with his/her own body. Cosmetic procedures are allowed, according the current legal codes, but are considered exceptions to the general rule of unavailability of the body, and to the definition of reasonable and proper limits placed by health authorities. Bariatric surgery is 
another example that deserves a deeper understanding of the right of a subject to modify his/her body and to modify it and to rebuild it fully, reducing the food absorption area, and on the right the surgeon, acting on behalf of the State and of health maintenance, to change physiology and to reset it, seeking weight loss and the pursuit of health ideals pursued by the State to its citizens and to citizens with themselves.

\section{The "Functionings Approach"}

The Brazilian researcher Maria Clara Dias [43], in her recent book "The Functionings Approach", brings a new definition of what would be the basis of modern bioethics. In addition to the essential knowledge of justice built by Rawls, Dworkin, Amartya Sen and Martha Nussbaum, the Brazilian university professor builds an inclusive, comprehensive bioethical framework and covers current issues that had not been addressed by the earlier theories. In this sense, obesity is not analysed simply as an objective issue, defined by numbers and limits as usual, such as Dworkin and Rawls might have suggested, and not as a free individual choice, as it might be understood by the view of Amarthya Sen or Nussbaum, but as an empirical and individual choice regarding the own body and its image, which would be based on the values and functionings of each individual, using the personal functional systems that each person has built for him/herself [44]-[49].

Thus, the ideal body and health status it would not be a state decision, but rather the result of the empirical analysis of the values of each person, in their specific context.

\section{Intermediate Solution: "Nudge"}

In the current medical literature the association between excess of weight and health problems in the general population is generally well established. The pathogenesis described for the obesity epidemic is multifactorial and involve especially 2 factors: 1 ) the food patterns that happened over the recent decades (a phenomenon also named "Nutritional Transition" and 2) the reduction in the levels of population mobility-physical inactivity, along with other reasons.

Would there a way of encouraging people to change their habits and to make better decisions for the development of healthier routines and choices more associated with healthy patterns?

"Behavioral Economics" studies show a way. Food choices, for instance, ARE strongly influenced the pattern of distribution of options in a restaurant. Placing fruits and vegetables at the beginning of a gondola of a restaurant, for example, increases the amount of consumption of such foods, considered healthier choices. On the opposite way, when placing pizzas and fried foods at the entrance, on the beginning of the available options, and moving apples and fruits to the end, a significant reduction in the choice of fruits happens, and a consequent increase in consumption of pizza and fried foods is measured. Shall public health policies suggest the distribution of food in public institutions, an improvement is quite 
likely to occur, perhaps imperceptible by the individual, and especially not restricting his/her decisions and options-but rather "nudging"- with a possible significant impact on the health of the populations [50].

Policies to influence individuals on making healthier decisions with a positive impact on a personal level were initially tested at a Cafeteria of the Harvard University, and such an approach is extensively studied by the Law School of that University, to stimulate healthier habits and avoiding to influence in a repressive way on the freedom of choice.

It could be argued that the state would again be interfering in the decisions of individuals. But a strong argument is that such influences would be mild, and most importantly, positive to every citizen's health, and not simply favorable to the State.

Applying public policies influences such as the "nudge" type to whole populations could be one of the fairest, effective and cheap available approaches towards overweight, respecting citizen's choices and their right to choose according to the functionings approach. In Brazil, the creation of "gyms for older people" in neighborhoods and the installation of specific equipments for such vulnerable populations encourages the participation of them in such activities, and would be examples of how to positively influence people into making healthier decisions. It is a way to prevent highly frequent diseases in the elderly, such as hypertension and obesity [51].

We claim that respecting the decisions of the individual could be reconciled with the interests of the State.

\section{Conclusions}

Obesity is a disease characterized by excessive accumulation of body fat and involves a variety of environmental and genetic factors in its etiology. In recent decades there has been a "Nutritional Transition" that, associated with an increased sedentary lifestyle, resulted in the obesity epidemic. Excess weight is a risk factor associated with health outcomes, which in turn raises high costs for the State.

The implementation of public policies towards obesity is becoming increasingly necessary and discussed by authorities throughout the world. It is always advisable not to interfere in the autonomy of each individual, their body weight and health behaviors. In this context, policies based on the "nudge" principle are supposed to be the most appropriate and effective, respecting ethical theories such as the functionings approach. Through preserving freedom of choice and mildly inducing the individual to make healthier decisions, the interests of the state and of the people are met in building fairer obesity control policies. Thus, it is reasonable that such strategies could be implemented and, over time, adapted to the reality of each population and culture.

\section{References}

[1] Federal Constitution of Brasil (1988) Brazilian Senate. Brasília, Brazil. 
[2] Malta, D.C., de Morais Neto, O.L. and de Silva Jr., J.B. (2011) Apresentação do plano de ações estratégicas para o enfrentamento das doenças crônicas não transmissíveis no Brasil, 2011 a 2022. Epidemiologia e Serviços de Saúde, 20, 425-438. https://doi.org/10.5123/S1679-49742011000400002

[3] Duncan, B.B., Chor, D., Aquino, E.M.L.D., Benseñor, I.J.M., Mill, J.G., Schmidt, M.I., Barreto, S.M., et al. (2012) Doenças crônicas não transmissíveis no Brasil: Prioridade para enfrentamento e investigação. Revista de Saúde Pública, 46, 126134. https://doi.org/10.1590/s0034-89102012000700017

[4] Lima, J.T.F. (1985) Risco de urbanização da febre amarela no Brasil. Cadernos de Saúde Pública, 1, 377-384. https://doi.org/10.1590/S0102-311X1985000300010

[5] Britto, N. (1995) Oswaldo Cruz: A construção de um mito na ciência brasileira. Editora Fiocruz, Rio de Janeiro.

[6] Sevcenko, N. (2014) A revolta da vacina: Mentes insanas em corpos rebeldes. Editora Cosac Naify, São Paulo.

[7] Porto, M.Y. (2003) Uma revolta popular contra a vacinação. Ciência e Cultura, 55, 53-54.

[8] Malta, D.C., Stopa, S.R., Iser, B.P.M., Bernal, R.T.I., Claro, R.M., Nardi, A.C.F., Monteiro, C.A., et al. (2015) Risk and Protective Factors for Chronic Diseases by Telephone Survey in Capitals of Brazil, Vigitel 2014. Revista Brasileira de Epidemiologia, 18, 238-255. https://doi.org/10.1590/1980-5497201500060021

[9] Steinberger, J. and Daniels, S.R. (2003) Obesity, Insulin Resistance, Diabetes, and Cardiovascular Risk in Children: An American Heart Association Scientific Statement from the Atherosclerosis, Hypertension, and Obesity in the Young Committee (Council on Cardiovascular Disease in the Young) and the Diabetes Committee (Council on Nutrition, Physical Activity, and Metabolism). Circulation, 107, 14481453. https://doi.org/10.1161/01.CIR.0000060923.07573.F2

[10] Bahia, L., Coutinho, E.S.F., Barufaldi, L.A., de Azevedo Abreu, G., Malhão, T.A., de Souza, C.P.R. and Araujo, D.V. (2012) The Costs of Overweight and Obesity-Related Diseases in the Brazilian Public Health System: Cross-Sectional Study. BMC Public Health, 12, 440. https://doi.org/10.1186/1471-2458-12-440

[11] Bahia, L., Cueto, M., Benchimol, J., Teixeira, L. A. and Cerqueira, R. C. (2014) Considerations on the Sistema Único de Saúde in the Twenty-First Century: An Interview with Lígia Bahia. História, Ciências, Saúde-Manguinhos, 21, 93-110. https://doi.org/10.1590/S0104-59702014000100005

[12] Foucault, M. (1982) The Subject and Power. Critical Inquiry, 8, 777-795. https://doi.org/10.1086/448181

[13] Foucault, M. (2012) The Birth of the Clinic. Routledge, Abingdon-on-Thames.

[14] Canguilhem, G. (1966) Le normal et lepathologique. Pressesuniversitaires de France, Paris, 91.

[15] Esposito, R. (2008) Bios: Biopolitics and Philosophy. Vol. 4, University of Minnesota Press, Minneapolis.

[16] Lemke, T. (2010) From State Biology to the Government of Life: Historical Dimensions and Contemporary Perspectives of "Biopolitics". Journal of Classical Sociology, 10, 421-438. https://doi.org/10.1177/1468795X10385183

[17] Revel, J. (2009) Identity, Nature, Life: Three Biopolitical Deconstructions. Theory, Culture \& Society, 26, 45-54. https://doi.org/10.1177/0263276409348854

[18] Agamben, G. (1998) Homo Sacer: Sovereign Power and Bare Life. Stanford University Press, Redwood City.

[19] Ojakangas, M. (2007) Impossible Dialogue on Bio-Power: Agamben and Foucault. 
Foucault Studies, No. 2, 5-28. https://doi.org/10.22439/fs.v0i2.856

[20] Collier, S.J. (2012) Neoliberalism as Big Leviathan, or...? A Response to Wacquant and Hilgers. Social Anthropology, 20, 186-195.

https://doi.org/10.1111/j.1469-8676.2012.00195.x

[21] Lepore, J. (2015) The Rule of History: Magna Carta, the Bill of Rights, and the Hold of Time. The New Yorker, 20.

[22] Katz, D.L. (2014) Perspective: Obesity Is Not a Disease. Nature, 508, S57. https://doi.org/10.1038/508S57a

[23] Hoyt, C.L., Burnette, J.L. and Auster-Gussman, L. (2014) "Obesity Is a Disease" Examining the Self-Regulatory Impact of This Public-Health Message. Psychological Science, 25, 997-1002.

[24] World Health Organization (June 2016) Obesity and Overweight: Fact Sheet. http://www.who.int/mediacentre/factsheets/fs311/en/

[25] National Center for Health Statistics (US) (1991) The International Classification of Diseases: 9th Revision, Clinical Modification: ICD-9-CM.

[26] Stoner, L. and Cornwall, J. (2014) Did the American Medical Association Make the Correct Decision Classifying Obesity as a Disease? The Australasian Medical Journal, 7, 462-464. https://doi.org/10.4066/AMJ.2014.2281

[27] Hubert, H.B., Feinleib, M., McNamara, P.M. and Castelli, W.P. (1983) Obesity as an Independent Risk Factor for Cardiovascular Disease: A 26-Year Follow-Up of Participants in the Framingham Heart Study. Circulation, 67, 968-977.

https://doi.org/10.1161/01.CIR.67.5.968

[28] Stockmarr, A., Hejgaard, T. and Matthiessen, J. (2016) Obesity Prevention in the Nordic Countries. Current Obesity Reports, 5, 156-165. https://doi.org/10.1007/s13679-016-0206-y

[29] Pollack A. A.M.A. Recognizes Obesity as a Disease [Internet]. 2013 [cited 2014 Nov 20].

http://www.nytimes.com/2013/06/19/business/ama-recognizes-obesity-as-a-disease. $\underline{\mathrm{html}}$

[30] Curtis, J.P., Selter, J.G., Wang, Y., Rathore, S.S., Jovin, I.S., Jadbabaie, F., et al. (2005) The Obesity Paradox: Body Mass Index and Outcomes in Patients with Heart Failure. Archives of Internal Medicine, 165, 55-61. https://doi.org/10.1001/archinte.165.1.55

[31] Habbu, A., Lakkis, N.M. and Dokainish, H. (2006) The Obesity Paradox: Fact or Fiction? The American Journal of Cardiology, 98, 944-948. https://doi.org/10.1016/j.amjcard.2006.04.039

[32] Prospective Studies Collaboration (2009) Body-Mass Index and Cause-Specific Mortality in 900,000 Adults: Collaborative Analyses of 57 Prospective Studies. The Lancet, 373, 1083-1096. https://doi.org/10.1016/S0140-6736(09)60318-4

[33] Saguy, A.C. (2012) What's Wrong with Fat? Oxford University Press, Oxford.

[34] Alpert, J.S. (2010) “So, Doctor, What's So Bad about Being Fat?" Combating the Obesity Epidemic in the United States. The American Journal of Medicine, 123, 1-2. https://doi.org/10.1016/j.amjmed.2009.05.027

[35] Sørensen, G. (2006) Liberalism of Restraint and Liberalism of Imposition: Liberal Values and World Order in the New Millennium. International Relations, 20, 251272. https://doi.org/10.1177/0047117806066702

[36] Steinmo, S. and Watts, J. (1995) It's the Institutions, Stupid! Why Comprehensive National Health Insurance Always Fails in America. Journal of Health Politics, Policy and Law, 20, 329-372. https://doi.org/10.1215/03616878-20-2-329 
[37] Fausto, B. (2014) A Concise History of Brazil. 2th Edition, Cambridge University Press, Cambridge, $472 \mathrm{p}$.

[38] The Economist (2009) Brazil Takes off. http://www.economist.com/node/14845197

[39] Atun, R., De Andrade, L.O.M., Almeida, G., Cotlear, D., Dmytraczenko, T., Frenz, P., et al. (2015) Health-System Reform and Universal Health Coverage in Latin America. The Lancet, 385, 1230-1247. https://doi.org/10.1016/S0140-6736(14)61646-9

[40] Bertranou, F.M. (1999) Are Market-Oriented Health Insurance Reforms Possible in Latin America?: The Cases of Argentina, Chile and Colombia. Health Policy, 47, 19-36. https://doi.org/10.1016/S0168-8510(99)00006-8

[41] Glass, A.S. (2014) Historical Aspects of Habeas Corpus. St. John's Law Review, 9, 3.

[42] Savage, M. (2015) Organ Transplantation: A Legal and Moral Analysis.

[43] Dias, M.C. (2004) Os direitos sociais básicos: Uma investigação filosófica da questão dos direitos humanos (No. 177). EDIPUCRS.

[44] Dias, M.C. (2015) Perspectiva Dos Funcionamentos, A-Por Uma Abordagem Moral Mais Inclusiva. Ed. Pirilampo.

[45] Dworkin, R. (2002) Sovereign Virtue: The Theory and Practice of Equality. Harvard University Press, Cambridge, MA.

[46] Deneulin, S. (2002) Perfectionism, Paternalism and Liberalism in Sen and Nussbaum's Capability Approach. Review of Political Economy, 14, 497-518. https://doi.org/10.1080/0953825022000009924

[47] Rawls, J. (2009) A Theory of Justice. Harvard University Press, Cambridge, MA.

[48] Sen, A. (2011) The Idea of Justice. Harvard University Press, Cambridge, MA.

[49] Nussbaum, M.C. (2011) Creating Capabilities. Harvard University Press, Cambridge, MA. https://doi.org/10.4159/harvard.9780674061200

[50] Leonard, T.C., Thaler, R.H. and Sunstein, C.R. (2008) Nudge: Improving Decisions about Health, Wealth, and Happiness. Constitutional Political Economy, 19, 356360. https://doi.org/10.1007/s10602-008-9056-2

[51] Hawkes, C., Smith, T.G., Jewell, J., Wardle, J., Hammond, R.A., Friel, S., Thow, A.M. and Kain, J. (2015) Smart Food Policies for Obesity Prevention. The Lancet, 385, 2410-2421. https://doi.org/10.1016/S0140-6736(14)61745-1

\section{Submit or recommend next manuscript to SCIRP and we will provide best service for you:}

Accepting pre-submission inquiries through Email, Facebook, LinkedIn, Twitter, etc. A wide selection of journals (inclusive of 9 subjects, more than 200 journals) Providing 24-hour high-quality service User-friendly online submission system Fair and swift peer-review system Efficient typesetting and proofreading procedure Display of the result of downloads and visits, as well as the number of cited articles Maximum dissemination of your research work

Submit your manuscript at: http://papersubmission.scirp.org/ Or contact ojemd@scirp.org 